\title{
Rottlerin promotes autophagy and apoptosis in gastric cancer cell lines
}

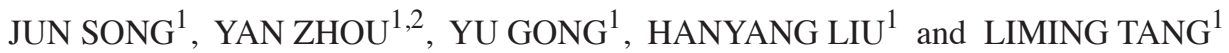 \\ ${ }^{1}$ Department of Gastrointestinal Surgery; ${ }^{2}$ Medical Research Center, The Affiliated Changzhou No. 2 People's Hospital \\ of Nanjing Medical University, Changzhou, Jiangsu 213000, P.R. China
}

Received November 3, 2017; Accepted July 11, 2018

DOI: $10.3892 / \mathrm{mmr} .2018 .9293$

\begin{abstract}
It is widely accepted that apoptosis is closely associated with cancer cell death. However, whether autophagy induces tumor cell death has not been fully elucidated. Various studies have discussed the antitumor properties of rottlerin in human malignancies. The current study aimed to investigate the effects of rottlerin, a natural product isolated from the kamala tree (Mallotus philipensis), on growth inhibition and autophagy in gastric cancer (GC) cell lines in vitro. The results of the present study demonstrated that rottlerin suppressed cell growth, induced autophagy and apoptosis, and reduced migration and invasion in the SGC-7901 and MGC-803 GC cell lines. Furthermore, rottlerin led to microtubule-associated protein 1 light chain $3 \beta$-II augmentation and the enrichment of autophagosomes. In addition, the protein expression levels of mechanistic target of rapamycin kinase and S-phase kinase-associated protein 2 were downregulated in GC cells following rottlerin treatment, which is associated with autophagy. The protein levels of caspase-3, cleaved-caspase-3, total poly (ADP-ribose) polymerase (PARP) and cleaved-PARP exhibited no marked alterations in the GC cells following rottlerin treatment, indicating that caspases were likely not involved in rottlerin-induced GC apoptosis. In summary, the results of the present study indicate that rottlerin may inhibit invasion and promote apoptosis in GC cells, which may be mediated by the activation of autophagy. Therefore, rottlerin may be of value in the treatment of GC.
\end{abstract}

Correspondence to: Dr Liming Tang, Department of Gastrointestinal Surgery, The Affiliated Changzhou No. 2 People's Hospital of Nanjing Medical University, 68 Gehu Road, Changzhou, Jiangsu 213000, P.R. China

E-mail: drtangliming@163.com

Abbreviations: GC, gastric cancer; PARP, poly(ADP-ribose) polymerase; mTOR, mechanistic target of rapamycin kinase; Skp2, S-phase kinase-associated protein 2; PKC $\delta$, protein kinase $\mathrm{C} \delta$

Key words: rottlerin, gastric cancer, apoptosis, autophagy, caspase

\section{Introduction}

Gastric cancer (GC) ranks fifth among all cancer types and is the third primary cause of cancer-associated mortality worldwide (1). Despite improvements in surgical and adjuvant therapies, the 5-year overall survival rate for patients with GC remains low; a poor prognosis is closely associated with the high metastasis and recurrence rate of GC. Furthermore, due to the development of drug resistance, as well as other factors, the benefits of chemotherapy and radiotherapy are limited $(2,3)$. Therefore, there is a requirement for the development of novel treatment methods for GC.

It was previously demonstrated that $25-48 \%$ of the currently available Food and Drug Administration-approved medical treatments are derived from plants (4-6), and a number of these plant-derived compounds exhibit anticancer properties. Rottlerin, also referred to as mallotoxin, is a polyphenolic compound derived from the kamala tree (Mallotus philipensis) (7). Initial studies demonstrated that rottlerin is a protein kinase $\mathrm{C} \delta(\mathrm{PKC} \delta)$ inhibitor (8-10). However, an increasing amount of evidence indicates that rottlerin may not only act as a specific PKCס inhibitor, but that it has multiple molecular targets and anticancer properties, including the inhibition of cell proliferation, promotion of apoptosis and inhibition of cell migration and invasion (11-13). However, the exact molecular mechanisms underlying the actions and anticancer effects of rottlerin remain to be elucidated.

In eukaryotic cells, autophagy, which causes organelle and protein degradation, constitutes an adaptive response under conditions of starvation or cellular stress (14). It is necessary to recycle the unnecessary or dysfunctional organelles and the misfolded or damaged proteins through basal autophagy in order to maintain genomic integrity and cellular homeostasis (15). The activation of autophagy is implicated in a variety of stress conditions, whereas its dysregulation is implicated in numerous pathophysiological processes, including cardiovascular diseases and cancer (16). In cancer, autophagy may serve two opposing roles. Specifically, autophagy may act as a prosurvival mechanism when tumor cells are subjected to injury by chemical or physical treatment, but it may also promote cancer cell death, acting as a tumor suppressor (17). A previous study demonstrated that autophagy is constitutively activated in cancer in response to treatment and may be involved in therapy-triggered apoptosis. Therefore, it is 
necessary to investigate the exact underlying mechanisms of autophagy in cancer (18).

Moretti et al (19) demonstrated that autophagy improved the effectiveness of anticancer therapy. Previous studies have demonstrated that rottlerin may promote apoptosis and autophagy in several types of cancer (20-22), but it remains unknown whether it exerts an anticancer effect on GC. To the best of our knowledge, the present study is the first to report antitumor effects of rottlerin on human GC cell lines. Furthermore, the molecular mechanism underlying the antitumor activity of rottlerin through activation of autophagy in GC cells was investigated, and the results indicate that rottlerin-induced autophagy may promote anticancer activity through cancer cell apoptosis.

\section{Materials and methods}

Cell culture and reagents. The SGC-7901 and MGC-803 human GC cell lines were purchased from the Type Culture Collection of the Chinese Academy of Sciences, Shanghai, China. The cells were cultured in RPMI-1640 medium (Gibco; Thermo Fisher Scientific, Inc., Waltham, MA, USA) with $10 \%$ fetal bovine serum (Gibco; Thermo Fisher Scientific, Inc.) and $1 \%$ streptomycin and penicillin in a humidified incubator at $5 \% \mathrm{CO}_{2}$ and $37^{\circ} \mathrm{C}$. Rabbit primary antibodies against $\mathrm{S}$-phase kinase-associated protein 2 (Skp2; cat. no. ab183039), mechanistic target of rapamycin kinase (mTOR; cat. no. ab32028), microtubule-associated protein 1 light chain $3 \beta$ (LC3)-II (cat. no. ab51520), caspase-3 (cat. no. ab13847), cleaved-caspase-3 (cat. no. ab2302), poly(ADP ribose) polymerase (PARP; cat. no. ab32138) and cleaved-PARP (cat. no. ab32064) were purchased from Abcam (Cambridge, UK). Rabbit primary antibodies against $\beta$-actin (cat. no. 4970) were purchased from Cell Signaling Technology, Inc. (Danvers, MA, USA). Secondary antibody (goat anti-rabbit; cat. no. sc2004) was obtained from Santa Cruz Biotechnology, Inc. (Dallas, TX, USA). Rottlerin and dimethyl sulfoxide (DMSO) were acquired from Sigma-Aldrich (Merck KGaA, Darmstadt, Germany). Rottlerin was dissolved in DMSO to generate a $10 \mathrm{mM}$ stock solution. Cells cultured with only $0.1 \%$ DMSO served as the control group.

Cell proliferation assay. Cell proliferation was measured with a Cell Counting Kit-8 (CCK-8) assay (Dojindo Molecular Technologies, Inc., Kumamoto, Japan). SGC-7901 and MGC-803 cells were seeded in 96-well plates at a density of 2,000 cells/well and incubated in a humid environment at $5 \% \mathrm{CO}_{2}$ and $37^{\circ} \mathrm{C}$ for $4 \mathrm{~h}$. Subsequently, the cells were exposed to $0,1,2,4,8$ and $16 \mu \mathrm{M}$ rottlerin for $12,24,48$ and $72 \mathrm{~h}$. CCK- 8 reagent was then added and incubated for $30 \mathrm{~min}$ at $37^{\circ} \mathrm{C}$. Absorbance of the colored formazan product, formed by mitochondrial dehydrogenases, was measured at a wavelength of $450 \mathrm{~nm}$.

Colony formation assay. SGC-7901 and MGC-803 cells were cultured in a 6-well plate at a density of 500 cells/well with $0,2,4$ and $8 \mu \mathrm{M}$ rottlerin at $37^{\circ} \mathrm{C}$ for 2 weeks. Cells treated with rottlerin-free medium served as the control group. After 2 weeks, the cells were fixed in $4 \%$ methanol for $15 \mathrm{~min}$ at room temperature. Cells were then stained with $0.1 \%$ crystal violet for $5 \mathrm{~min}$ at room temperature and imaged using a light microscope (Olympus Corporation, Tokyo, Japan) at x40 magnification.

Cell cycle assay. SGC-7901 and MGC-803 cells were seeded at a density of $1 \times 10^{6} / \mathrm{ml}$, and then harvested following treatment with 0,24 and $8 \mu \mathrm{M}$ rottlerin at $37^{\circ} \mathrm{C}$ for $24 \mathrm{~h}$. The cells were fixed in $70 \%$ ethanol at $4^{\circ} \mathrm{C}$ overnight. The fixed cells were centrifuged at $1,000 \times \mathrm{g}$ for $15 \mathrm{~min}$ at room temperature and washed with cold PBS three times. The cells were incubated with $50 \mu \mathrm{g} / \mathrm{ml} \mathrm{RNase} \mathrm{A}$ at $37^{\circ} \mathrm{C}$ for $30 \mathrm{~min}$. Then cells were incubated with $100 \mu \mathrm{g} / \mathrm{ml}$ propidium iodide (PI) in the dark at $4^{\circ} \mathrm{C}$ for $30 \mathrm{~min}$. The DNA content was quantified by FCM (BD CellQuest Pro; BD Biosciences, Franklin Lakes, NJ, USA). The percentages of cells in the $\mathrm{G}_{0}-\mathrm{G}_{1}, \mathrm{~S}$ and $\mathrm{G}_{2}-\mathrm{M}$ phases were compared with the control group.

Apoptosis assay. SGC-7901 and MGC-803 cells were cultured at $1 \times 10^{6} / \mathrm{ml}$ in 6-well plates following treatment with 0,24 and $8 \mu \mathrm{M}$ rottlerin at $37^{\circ} \mathrm{C}$ for $24 \mathrm{~h}$. Cells were collected, washed twice with cold PBS and resuspended in $100 \mu$ l binding buffer containing $5 \mu \mathrm{l}$ fluorescein isothiocyanate-conjugated anti-Annexin V antibody and $5 \mu \mathrm{l}$ PI using a FITC-Annexin V Apoptosis Detection kit (BD Biosciences). Apoptosis was assessed using a FACS Calibur flow cytometer (BD CellQuest Pro; BD Biosciences). The percentages of apoptotic cells were compared with the control group.

Cell migration and invasion assays. SGC-7901 and MGC-803 cells were cultured at $1 \times 10^{6} / \mathrm{ml}$ in 6 -well plates. Migration was assessed using a wound healing assay that was performed following treatment with 0,24 and $8 \mu \mathrm{M}$ rottlerin at $37^{\circ} \mathrm{C}$ for 0 and $24 \mathrm{~h}$. A scratch was created in a culture plate using the tip of a pipette (Thermo Fisher Scientific, Inc.). Cells were incubated at $37^{\circ} \mathrm{C}$ and images were captured after 0 and $24 \mathrm{~h}$. For the cell invasion assay, GC cells were incubated with $0,2,4$ and $8 \mu \mathrm{M}$ rottlerin at $37^{\circ} \mathrm{C}$ for $24 \mathrm{~h}$ and then harvested. $5 \times 10^{4}$ cells were added to the upper chambers of a Transwell assay plate, which were coated with Matrigel, containing $200 \mu \mathrm{l}$ serum-free medium. The lower chambers contained complete medium with $0,2,4$ and $8 \mu \mathrm{M}$ rottlerin. After $48 \mathrm{~h}$, the cells in the lower chamber were fixed in cold methanol, stained with $0.1 \%$ crystal violet and images were captured.

Reverse transcription-quantitative polymerase chain reaction (RT-qPCR) analysis. SGC-7901 and MGC-803 cells were incubated with $0,2,4$ and $8 \mu \mathrm{M}$ rottlerin at $37^{\circ} \mathrm{C}$ for $24 \mathrm{~h}$. Total RNA was extracted using TRIzol reagent (Invitrogen; Thermo Fisher Scientific, Inc.), according to the manufacturer's protocol. cDNA was synthesized using a PrimeScript ${ }^{\mathrm{TM}}$ RT Reagent kit (Takara Biotechnology Co., Ltd., Dalian, China) at $37^{\circ} \mathrm{C}$ for $15 \mathrm{~min}$, followed by $85^{\circ} \mathrm{C}$ for $5 \mathrm{sec}$, determined at $4^{\circ} \mathrm{C}$ and qPCR was conducted using a SYBR ${ }^{\circledR}$ Premix Ex Taq $^{\mathrm{TM}}$ kit (Takara Biotechnology Co., Ltd.) on a Bio-Rad iQ5 Real-Time PCR system (Bio-Rad Laboratories, Inc., Hercules, CA, USA). The following thermocycling conditions were used for the PCR: Initial denaturation at $95^{\circ} \mathrm{C}$ for $10 \mathrm{~min}$, followed by 40 cycles of $95^{\circ} \mathrm{C}$ for $15 \mathrm{sec}$ and $60^{\circ} \mathrm{C}$ for $1 \mathrm{~min}$. The primer sequences for amplification were as follows: mTOR, 5'-AGGCCGCATTGTCTCTATCAA-3' (forward) and 5'-GCAGTAAATGCAGGTAGTCATCCA-3' (reverse); Skp2, 
5'-GCTGCTAAAGGTCTCTGGGT-3' (forward) and 5'-AGG CTTAGATTCTGCACTTG-3' (reverse); and GAPDH, 5'-ACC CAGAAGACTGTGGATGG-3' (forward) and 5'-CAGTGA GCTTCCCGTTCAG-3' (reverse). The relative expression was calculated using the $2^{-\Delta \Delta \mathrm{Cq}}$ method, with GAPDH used as the internal control (23).

Autophagy assay. SGC-7901 and MGC-803 cells were seeded in 96-well plates at a density of 2,000 cells/well in rottlerin-containing medium (0,2, 4 and $8 \mu \mathrm{M}$ rottlerin) at $37^{\circ} \mathrm{C}$ for $24 \mathrm{~h}$, followed by incubation with the Autophagosome Detection kit (Sigma-Aldrich; Merck KGaA). Medium was removed from the cells and $100 \mu l$ of the autophagosome detection reagent working solution was added to each well and cells were incubated at $37^{\circ} \mathrm{C}$ with $5 \% \mathrm{CO}_{2}$ for $30 \mathrm{~min}$. Subsequently cells were washed with Wash Buffer 3 times by gently adding $100 \mu \mathrm{l}$ of Wash Buffer to each well and cells were immediately imaged using a fluorescence microscope (Olympus Corporation, Tokyo, Japan). Autophagy was visualized as the bright blue staining of autophagic vacuoles.

Western blot analysis. Following treatment with $0,2,4$ and $8 \mu \mathrm{M}$ rottlerin at $37^{\circ} \mathrm{C}$ for $24 \mathrm{~h}$, radioimmunoprecipitation assay lysis buffer (Beyotime Institute of Biotechnology, Haimen, China) was added for the extraction of proteins from GC cells for $40 \mathrm{~min}$ on ice. The supernatants incubated in $4^{\circ} \mathrm{C}$ for $30 \mathrm{~min}$ and centrifuged at $13,000 \mathrm{x}$ g at $4^{\circ} \mathrm{C}$ for $15 \mathrm{~min}$, the protein concentrations were measured by Enhanced BCA Protein Assay kit (Beyotime Institute of Biotechnology, Shanghai, China). Protein $(20 \mu \mathrm{g})$ was loaded and separated via $12.5 \%$ SDS-PAGE, with a volume of $20 \mu \mathrm{l}$ per well. The proteins were transferred onto $0.22-\mu \mathrm{m}$ polyvinylidene fluoride membranes. The membranes were subsequently incubated with primary antibodies at a dilution of 1:1,000 at $4^{\circ} \mathrm{C}$ overnight, followed by incubation with secondary antibodies diluted in TBS-Tween-20 (0.1\% Tween-20) at room temperature for $1.5 \mathrm{~h}$. Enhanced chemiluminescence reagent (Pierce; Thermo Fisher Scientific, Inc.) was used to visualize the bound antibodies using the ChemiDoc imaging system (Abcam). Protein band intensities were semi-quantitated with ImageJ software (version 1.46r; National Institutes of Health, Bethesda, MD, USA) and normalized to $\beta$-actin.

Statistical analysis. Data are presented as the mean \pm standard error. Each experiment was performed three times independently. Data analysis was performed by ANOVA using GraphPad Prism 5 software (GraphPad Software, Inc., La Jolla, CA, USA). Bonferroni's test was used as a post hoc test. $\mathrm{P}<0.05$ was considered to indicate a statistically significant difference.

\section{Results}

Rottlerin suppresses the proliferation of GC cells in a timeand dose-dependent manner. To investigate whether rottlerin suppressed the proliferation of GC cells, a CCK-8 assay was performed using SGC-7901 and MGC-803 cells following rottlerin treatment. The results demonstrated that rottlerin inhibited GC cell proliferation in a dose-dependent manner (Fig. 1A and B). Relative cell viability is presented in Fig. 1C. Rottlerin at $1 \mu \mathrm{M}$ exerted no obvious suppressive effect on GC cells, $16 \mu \mathrm{M}$ rottlerin caused cell death, and 2, 4 and $8 \mu \mathrm{M}$ rottlerin was used as the experimental group.

Rottlerin on clonogenic capacity in GC cells. The colony formation assay revealed that rottlerin suppressed the clonogenic capacity of GC cells compared with the control group (Fig. 1D).

Rottlerin promotes apoptosis and cell cycle arrest in GC cells. It was previously reported that rottlerin promoted cell cycle arrest and apoptosis in breast cancer cells (11). To further elucidate the effects of rottlerin on cell cycle distribution and apoptosis in GC cells, the percentage of GC cells in each cell cycle phase following rottlerin treatment was determined through PI staining and flow cytometry. As presented in Fig. 2A and B, rottlerin led to evident $\mathrm{G}_{0} / \mathrm{G}_{1}$ phase arrest in GC cells. Rottlerin at 2,4 and $8 \mu \mathrm{M}$ led to a $\mathrm{G}_{1}$ cell population increase from $45.13 \pm 2.21 \%$ to $53.43 \pm 1.81,60.45 \pm 3.07$ and $66.79 \pm 1.94 \%$, respectively, in SGC-7901 cells. Similarly, 2, 4 and $8 \mu \mathrm{M}$ rottlerin caused a $\mathrm{G}_{1}$ cell population increase from $42.21 \pm 1.86 \%$ to $50.41 \pm 1.87,56.42 \pm 2.38$ and $65.82 \pm 2.22 \%$, respectively, in MGC-803 cells. Furthermore, flow cytometry following annexin V-FITC and PI staining revealed that, following treatment with rottlerin at 2,4 and $8 \mu \mathrm{M}$, the apoptosis rate of MGC- 803 cells were increased from $2.68 \pm 1.00 \%$ to $8.57 \pm 0.80,12.27 \pm 1.06$ and $15.19 \pm 0.92 \%$, the SGC-7901 cell apoptosis rate from $3.20 \pm 1.60 \%$ to $16.01 \pm 1.15,23.83 \pm 1.67$ and $29.99 \pm 1.64 \%$, respectively (Fig. $2 \mathrm{C}$ and D). Taken together, these results indicate that rottlerin promoted cell cycle arrest and apoptosis in GC cells.

Rottlerin inhibits the migration and invasion of GC cells. To determine the effects of rottlerin on the migratory activity of GC cells, a wound-healing assay was conducted. The results demonstrated that rottlerin inhibited migration in both types of GC cells in a dose-dependent manner (Fig. 3A and B). To confirm the effect of rottlerin on the invasion ability of GC cells, a Transwell assay was conducted using Matrigel (Fig. 3C and D). Rottlerin reduced the number of GC cells invading through the Matrigel, compared with the control group (Fig. 3C and D). These results indicate that rottlerin inhibited the migration and invasion ability of GC cells.

Effect of rottlerin on cell morphology. GC cells treated with 2, 4 and $8 \mu \mathrm{M}$ rottlerin were examined under a light microscope (Fig. 4A). Cells treated with rottlerin were fewer compared with the control group, as well as smaller and more spindle-shaped, with less cytoplasm. Membrane ruffling was reduced, with a contractive cell appearance. Therefore, the morphology of GC cells treated with rottlerin was clearly affected. The observations were consistent with those in rat C6 glioblastoma cells, as reported by Parmer et al (24).

Rottlerin induces autophagy in GC cells. GC cells treated with 2,4 and $8 \mu \mathrm{M}$ rottlerin were used to investigate the association between rottlerin and autophagy. LC3-II expression levels were detected by western blotting and fluorescence microscopy was used to evaluate autophagosome formation. As demonstrated by examination with a fluorescence microscope, the number of autophagosomes was increased in the rottlerin-treated GC cells compared with the control group, as demonstrated 

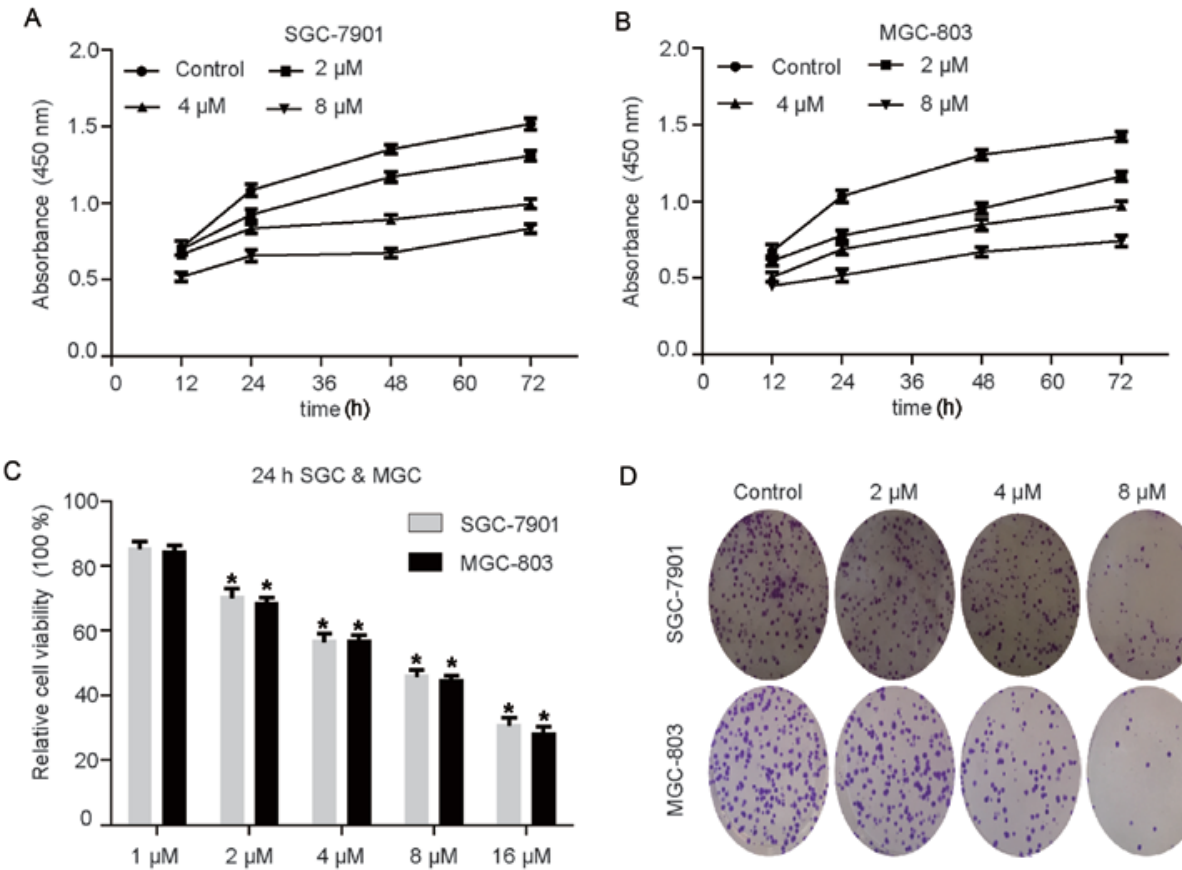

D

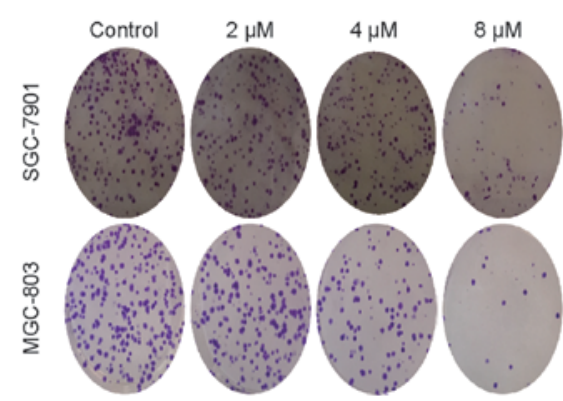

Figure 1. Rottlerin suppresses GC cell proliferation in a dose-dependent manner. CCK-8 and colony formation assays were conducted to assess the proliferation of GC cells following treatment with rottlerin. Proliferation of (A) SGC-7901 and (B) MGC-803 cells, as determined by CCK-8 assays. (C) Cell viability was assessed in SGC-7901 and MGC-803 cells using CCK-8 assays. (D) Representative images of colony formation assay results. Data are presented as the mean \pm standard error of the mean of at least three independent experiments. " $\mathrm{P}<0.05$ vs. control group. GC, gastric cancer; CCK-8, Cell Counting Kit- 8 ; SGC, SGC-7901 cells; MGC, MGC-803 cells.
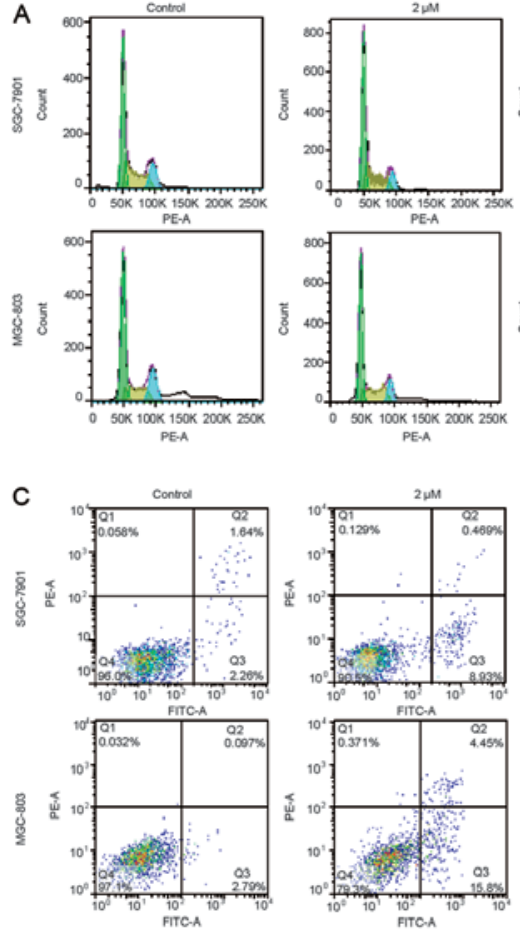
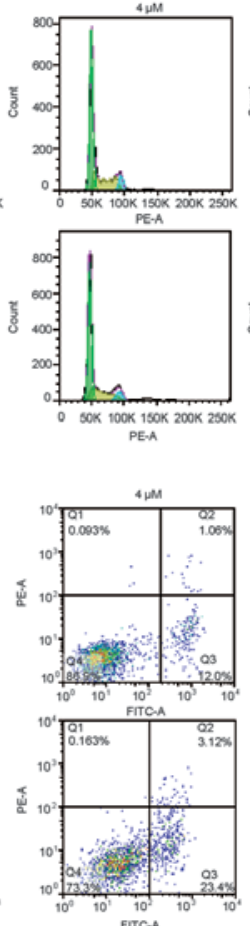
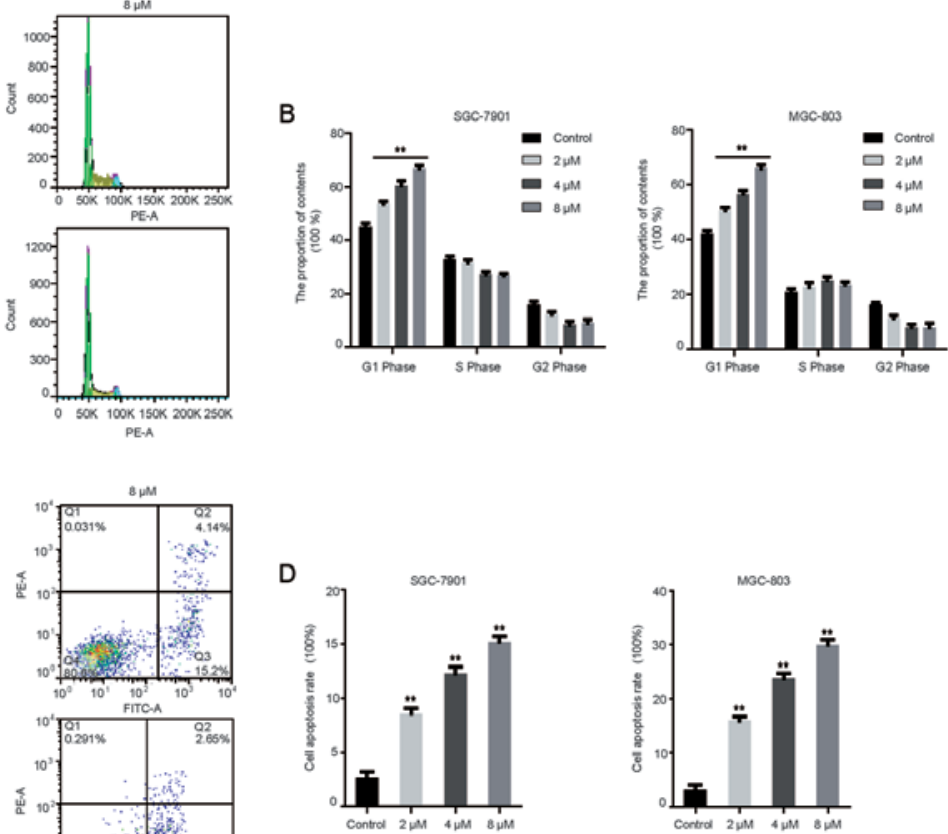

Figure 2. Rottlerin arrests the cell cycle and induces apoptosis in a concentration-dependent manner in GC cells. Flow cytometry was used to detect cell cycle arrest and apoptosis in GC cells following rottlerin treatment. (A) Representative flow cytometry plots following PI staining for cell cycle analysis. (B) Quantification of cell cycle analysis. (C) Representative flow cytometry plots following annexin V-FITC/PI staining for apoptosis analysis. (D) Quantification of cell apoptosis. Data are presented as the mean \pm standard error of the mean of at least three independent experiments. ${ }^{* *} \mathrm{P}<0.01$ vs. control group. GC, gastric cancer; PI, propidium iodide; FITC, fluorescein isothiocyanate.

by increased light blue fluorescence, whereas the light green cells were those without autophagosomes. (Fig. 4B). During autophagosome formation, the microtubule-associated LC3-I is converted to the membrane-bound form LC3-II (25). The 


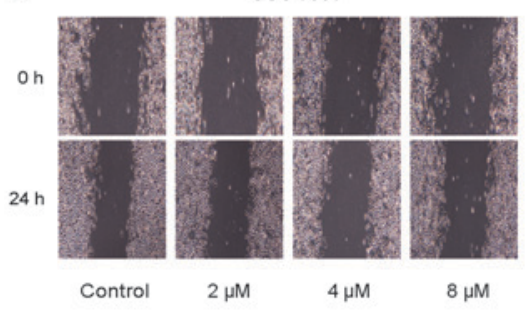

C

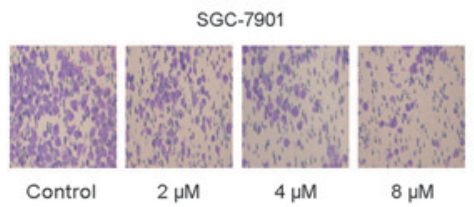

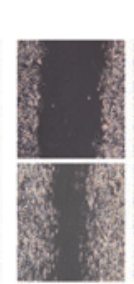

Control
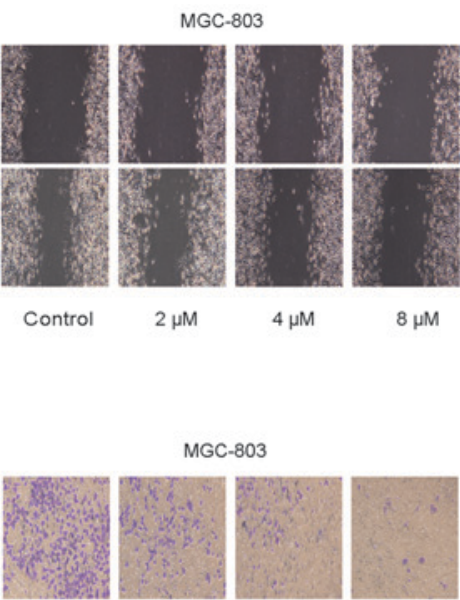

Control

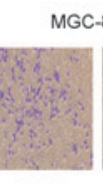

C-803

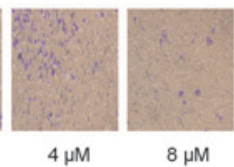

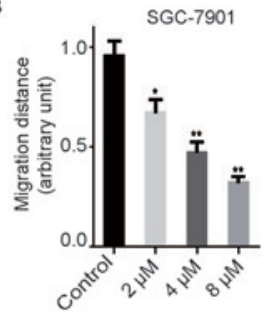

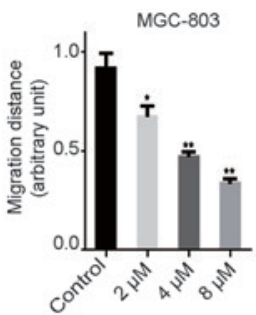

D

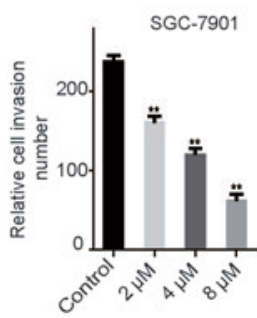

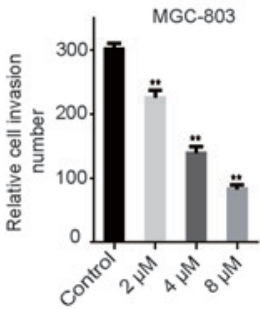

Figure 3. Concentration-dependent inhibition of GC cell migration and invasion by rottlerin. Wound-healing and Matrigel invasion assays were conducted to determine cell migration and invasion abilities following treatment with rottlerin. (A) Representative images of wound healing assay results captured at 0 and $24 \mathrm{~h}$. (B) Quantitative statistical analysis of wound healing results demonstrated the inhibitory effect of rottlerin on GC cell migration ability. (C) Representative images of cells in lower chambers following Matrigel invasion assay. (D) Quantitative statistical analysis demonstrated the suppressive effect of rottlerin on GC cell invasion ability. The images were captured by a light microscope at x200 magnification. Data are presented as the mean \pm standard error of the mean of at least three independent experiments. ${ }^{*} \mathrm{P}<0.05$ and ${ }^{* *} \mathrm{P}<0.01$ vs. control group. GC, gastric cancer.

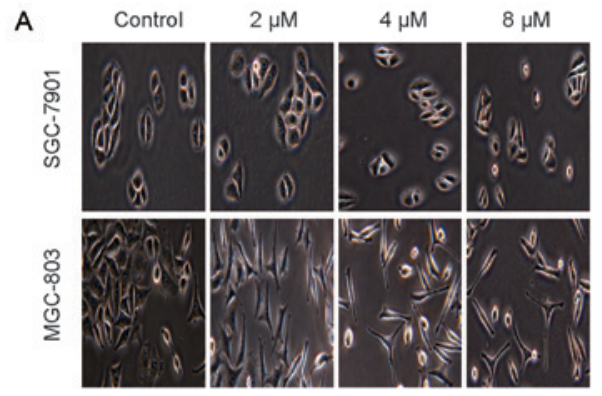

C

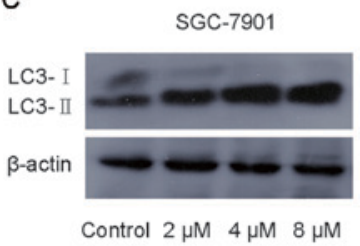

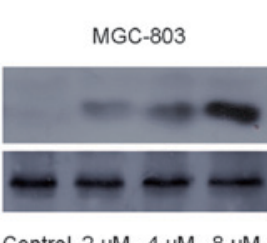

Control $2 \mu \mathrm{M} 4 \mu \mathrm{M} 8 \mu \mathrm{M}$
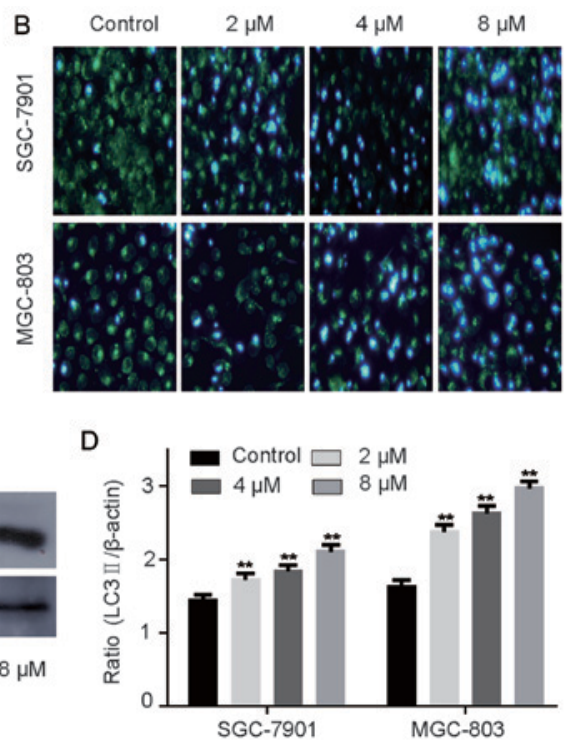

Figure 4. Dose-dependent effect of rottlerin on GC cell morphology and autophagy. (A) GC cells were cultured with rottlerin for $24 \mathrm{~h}$ and then examined under a light microscope at x200 magnification. (B) An autophagy assay revealed the number of autophagosomes in GC cells cultured with rottlerin at x200 magnification. Bright blue staining indicates autophagic cells in green light background. (The green cells indicate the cells without autophagosomes, and the bright blue staining indicates autophagic cells.) (C) Representative western blot bands for the protein expression of LC3-I and -II following rottlerin treatment in GC cells. (D) Densitometric and statistical analysis of LC3-II protein expression in GC cells. Protein quantification data are presented as histograms and were normalized to $\beta$-actin. Data are presented as the mean \pm standard error of the mean of at least three independent experiments. ${ }^{* *}<<0.01$ vs. control group. GC, gastric cancer; LC3, microtubule-associated protein 1 light chain $3 \beta$.

LC3-II expression level was increased in GC cells following treatment with rottlerin and the quantitative results revealed significant differences compared with the control cells (Fig. 4C and D). Therefore, the results indicated that rottlerin may promote autophagy in GC cells.

Rottlerin causes apoptotic cell death independently of caspase. Rottlerin-induced apoptosis has been reported in several cancer cell lines $(11,26)$. The caspase cascade functions in apoptosis induction and completion (27,28). Western blotting was conducted to evaluate caspase-3 and PARP expression, which exhibited no obvious increase in GC cells following treatment with rottlerin (Fig. 5). Cleaved-caspase-3 and PARP were also evaluated, and no cleaved-caspase- 3 expression was detected in GC cells treated with rottlerin (Fig. 5). Cleaved-PARP was detected in GC cells, but the difference between rottlerin-treated GC cells and control cells was not statistically significant (Fig. 5). Similar observations were 


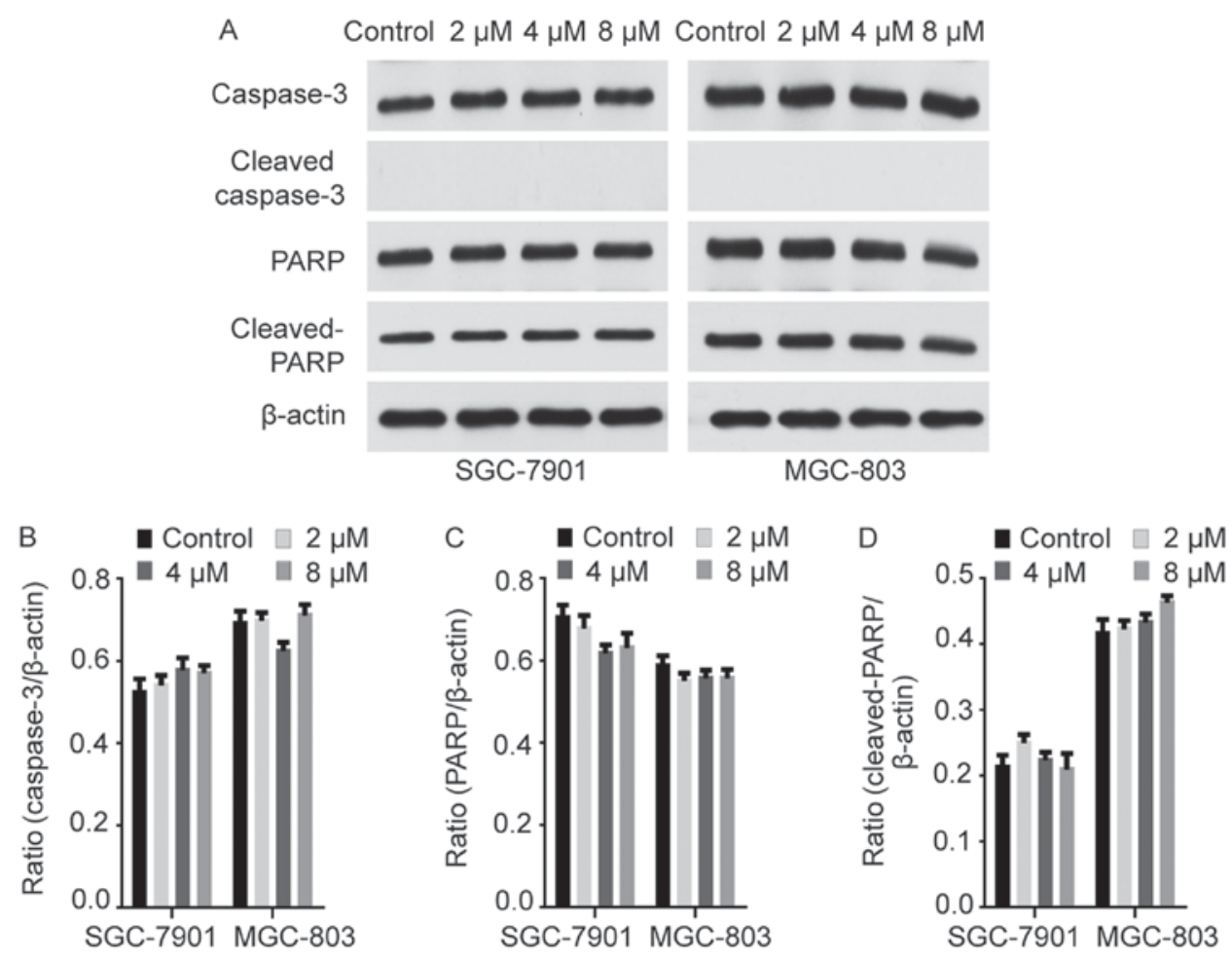

Figure 5. Apoptosis-associated protein expression levels in GC cells following rottlerin treatment. (A) Western blotting was performed to measure the expression of the apoptosis-associated proteins caspase-3, PARP, cleaved-caspase-3 and cleaved-PARP in GC cells following treatment with rottlerin for $24 \mathrm{~h}$. Densitometric and statistical analysis of the protein expression of (B) caspase-3, (C) PARP and (D) cleaved-PARP were performed, and the expression was normalized to $\beta$-actin. Data are presented as the mean \pm standard error of the mean of at least three independent experiments. GC, gastric cancer; PARP, poly(ADP-ribose) polymerase.

reported by Torricelli et al (29). Therefore, rottlerin may promote apoptosis independently of caspase in GC cells.

Rottlerin downregulates Skp2 and mTOR protein expression. Several studies have reported that rottlerin inhibits Skp2 protein expression in pancreatic and breast cancer $(11,13)$. Wu et al (30) observed that Skp2 promoted autophagy through inhibition of mTOR complex 1 (mTORC1). The expression levels of mTOR and Skp2 were evaluated via RT-qPCR (Fig. 6A and B) and western blot assays (Fig. 6C-E) in GC cells treated with rottlerin. The mRNA levels of mTOR and Skp2 were downregulated following treatment with rottlerin for $24 \mathrm{~h}$ (Fig. 6A and B). The protein levels of mTOR and Skp2 following rottlerin treatment were consistent with the results for mRNA expression levels in GC cells (Fig. 6C-E). Consistent with previous studies, these results demonstrate that rottlerin may reduce the expression of Skp2 via the inhibition of mTOR expression in order to promote autophagy in GC cells $(11,13)$.

\section{Discussion}

Due to the development of chemotherapy resistance, numerous phytochemical compounds derived from edible plants and their synthetic derivatives have attracted attention due to their unique anticancer properties and have been recommended for cancer therapy (31-33). However, information focusing on the anticancer properties of phytochemical compounds is limited; therefore, it is necessary to elucidate the mechanisms underlying their antitumor effects (34). The anticancer effects of phytochemical compounds are widely recognized, and phytochemicals may enhance the effectiveness of chemotherapy and decrease the toxic side effects $(35,36)$. Rottlerin is a traditional Indian medicinal plant that was first identified as a PKC $\delta$-selective inhibitor by Gschwendt et al (7) in 1994 and has been largely overlooked, despite its potential involvement in multiple signaling pathways. Further research demonstrated that rottlerin may inhibit several pathways in a PKC $\delta$-independent manner. Basu et al (37) demonstrated that rottlerin was able to induce the apoptosis of HeLa cells through downregulation of caspase-2 via a PKC 8 -independent pathway. Lin et al (12) reported that rottlerin inhibited follicular thyroid carcinoma cell migration independent of PKCD. Yin et al (11) reported that rottlerin exerted anticancer effects partially through Skp2 inactivation in breast cancer cells, while Su et al (13) demonstrated that rottlerin inhibited the proliferation and invasion of pancreatic cancer cells via the inactivation of Skp2. In addition, Zhao et al (38) demonstrated that rottlerin suppressed non-small-cell lung cancer through the downregulation of transcriptional co-activator with PDZ-binding motif. Similarly, the results of the current study revealed that rottlerin suppressed cancer cell proliferation, promoted apoptosis, and inhibited migration and invasion.

Apoptosis, a process that is crucial for the maintenance of normal tissue homeostasis, usually occurs as a consequence of either extracellular stimuli (extrinsic pathway) or intracellular stimuli (intrinsic or mitochondrial pathway) $(39,40)$ and is closely associated with the design of chemotherapeutics. Shukla et al (41) observed that apigenin promoted the interaction between Ku70 and Bcl-2-associated X, and induced 
A

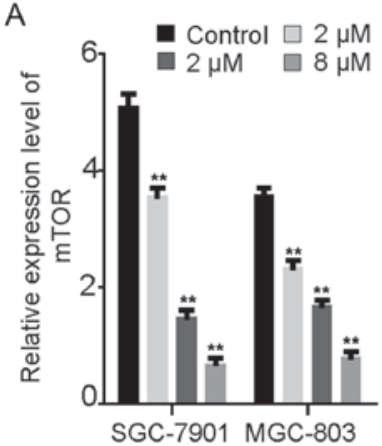

C

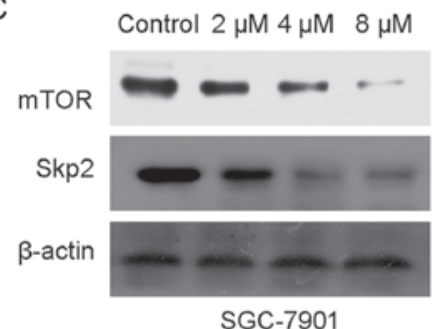

$\mathrm{D}$

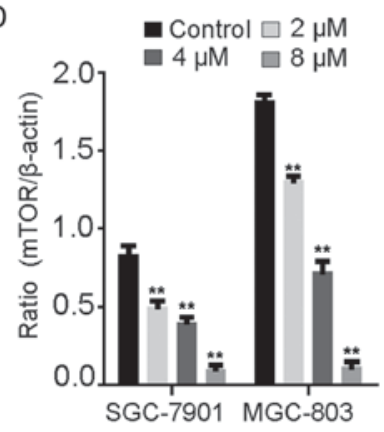

B

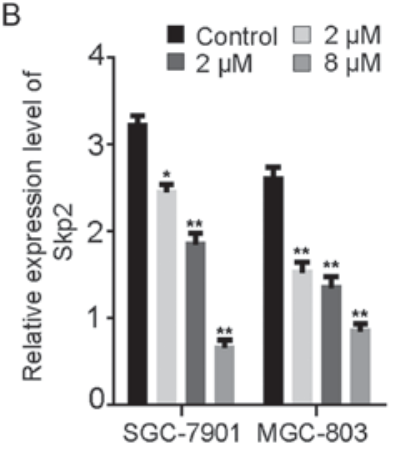

Control $2 \mu \mathrm{M} 4 \mu \mathrm{M} 8 \mu \mathrm{M}$

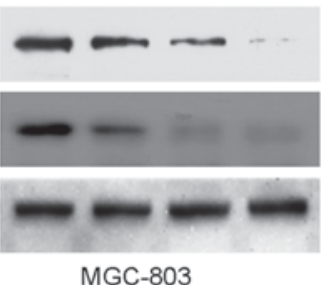

$E$

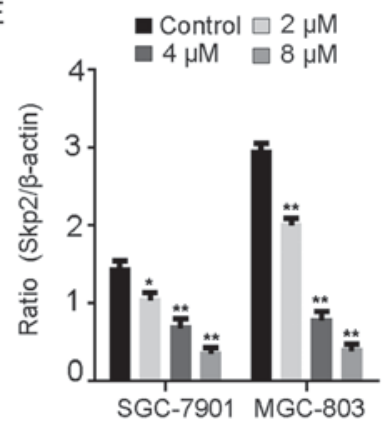

Figure 6. Expression levels of cancer-associated proteins in GC cells were evaluated via RT-qPCR and western blot analysis. Relative mRNA expression levels of (A) mTOR and (B) Skp2 were measured by RT-qPCR in GC cells following treatment with rottlerin. (C) Representative western blot bands for the protein expression of mTOR and Skp2 in GC cells following treatment with rottlerin for $24 \mathrm{~h}$. Densitometric and statistical analysis of the protein expression of (D) mTOR and (E) Skp2 was performed, and the expression was normalized to $\beta$-actin. Data are presented as the mean \pm standard error of at least three independent experiments. ${ }^{*} \mathrm{P}<0.05$ and ${ }^{* *} \mathrm{P}<0.01$ vs. control group. GC, gastric cancer; RT-qPCR, reverse transcription-quantitative polymerase chain reaction; mTOR, mechanistic target of rapamycin kinase; Skp2, S-phase kinase-associated protein 2.

prostate cancer cell apoptosis via apoptosis protein suppression. Caspases are involved in cell proliferation, migration, cytoskeletal organization and immunological effects $(42,43)$. Disorders of the activity of caspases have been associated with multiple pathological processes, including cancer (44). Rottlerin may induce apoptosis through suppression of phosphoinositide 3-kinase (PI3K)/Akt/mTOR signaling or caspase cascade activation (45). The present study revealed no significant alterations in caspase-3, PARP, cleaved-caspase-3 and cleaved-PARP protein expression, indicating that rottlerin may promote apoptosis in GC cells through a caspase-independent pathway. Furthermore, the present results demonstrated that the percentage of SGC-7901 and MGC-803 cells in the $\mathrm{G}_{1}$ phase increased as the concentration of rottlerin increased, but there was no significant difference between the control and any rottlerin groups for $\mathrm{S}$ and $\mathrm{G}_{2}$ phases. It suggested that

rottlerin may have caused cell cycle arrest in the $\mathrm{G}_{1}$ phase. And rottlerin may have enhanced the $\mathrm{G}_{1} / \mathrm{S}$ checkpoint activities and weakened the $\mathrm{G}_{2} / \mathrm{M}$ checkpoint activities, causing more SGC-7901 and MGC-803 cells to remain in $\mathrm{G}_{1}$ phase, and thus performing a function of preventing cell proliferation. But this needs to be verified with further experiments in future studies.

Autophagy, which involves the degradation of superfluous or damaged organelles and proteins, is an evolutionarily conserved lysosomal degradation process $(46,47)$. Macroautophagy, chaperone-mediated autophagy and microautophagy, the major identified types of autophagy, vary in terms of delivery method of the cargo to the lysosome and physiological function (48). Autophagy is closely associated with cell survival, maintenance and various pathological processes, among which cancer has received the most attention (49-52). However, the role of autophagy in tumors remains controversial (53). Song et al (21) demonstrated that rottlerin induced autophagy and apoptotic cell death in human fibrosarcoma cells in a PKC $\delta$-independent manner. In the present study, western blotting and autophagosome staining revealed that rottlerin promoted autophagy in a dose-dependent manner, indicating the potential anticancer function of rottlerin in GC.

The connection between apoptosis and autophagy has not been fully elucidated, however, a growing body of evidence indicates the presence of a molecular crosstalk between these two pathways $(54,55)$. Our results demonstrated that rottlerin increased cell apoptosis and promoted autophagy, but future investigations should focus on the interplay of apoptosis and autophagy caused by rottlerin in GC. Several studies have demonstrated that rottlerin may inhibit cancer cell proliferation and progression via downregulation of the Skp2 protein $(11,13)$. Wu et al (30) observed that Skp2 promoted autophagy through inhibition of mTORC1. Similarly, the present study identified Skp2 downregulation in GC cells following treatment with rottlerin. Kumar et al (20) demonstrated that rottlerin promoted apoptosis and autophagy in prostate cancer via PI3K/Akt/mTOR signaling. A similar result was reported by Singh et al (45) in pancreatic cancer. The present study demonstrated that the mRNA and protein levels of mTOR and Skp2 were both decreased following rottlerin treatment. It is not clear whether there is a connection between them, and this should be further investigated in future research. Future investigations should focus on upstream and downstream effectors of PI3K/Akt/mTOR signaling and the Skp2 protein, in order to further elucidate the specific mechanism of action underlying the role of rottlerin in GC, alone or in combination with chemotherapeutic drugs, and to investigate the crosstalk between autophagy and apoptosis signaling pathways, as well as apoptosis pathways other than the caspase cascade. Furthermore, in vivo experiments are required to verify these results of rottlerin treatment observed in vitro.

In conclusion, to the best of our knowledge, the present study is the first to demonstrate that rottlerin induces apoptosis and autophagy in GC and, therefore, that treatment with rottlerin may be an effective approach to GC treatment.

\section{Acknowledgements}

Not applicable. 


\section{Funding}

The present study was funded by the Changzhou Health and Family Planning Commission Project (grant nos. ZD201606 and QN201711) and the Nanjing Medical University School Fund (grant nos. 2016NJMUZD081 and 2017NJMU043).

\section{Availability of data and materials}

All data generated and analyzed during the present study are available from the corresponding author on reasonable request.

\section{Authors' contributions}

JS and LT designed the study and wrote the manuscript. JS, YZ, YG and HL carried out the experiments and performed the statistical analysis. JS and YZ made contributions in modification the manuscript. All the authors have read and approved the final manuscript.

\section{Ethics approval and consent to participate}

Not applicable.

\section{Patient consent for publication}

Not applicable.

\section{Competing interests}

The authors declare that they have no competing interests.

\section{References}

1. Siegel R, Ma J, Zou Z and Jemal A: Cancer statistics, 2014. CA Cancer J Clin 64: 9-29, 2014.

2. Zeng YJ, Zhang CD and Dai DQ: Impact of lymph node micrometastasis on gastric carcinoma prognosis: A meta-analysis. World J Gastroenterol 21: 1628-1635, 2015.

3. Deng JY and Liang H: Clinical significance of lymph node metastasis in gastric cancer. World J Gastroenterol 20: 3967-3975, 2014.

4. Russo GL: Ins and outs of dietary phytochemicals in cancer chemoprevention. Biochem Pharmacol 74: 533-544, 2007.

5. Orlikova B and Diederich M: Power from the garden: Plant compounds as inhibitors of the hallmarks of cancer. Curr Med Chem 19: 2061-2087, 2012.

6. Ji S, Orlikova B and Diederich M: Non-edible plants as an attractive source of compounds with chemopreventive potential J Cancer Prev 19: 1-6, 2014.

7. Gschwendt M, Müller HJ, Kielbassa K, Zang R, Kittstein W, Rincke G and Marks F: Rottlerin, a novel protein kinase inhibitor. Biochem Biophys Res Commun 199: 93-98, 1994.

8. Maioli E, Torricelli C and Valacchi G: Rottlerin and cancer: Novel evidence and mechanisms. ScientificWorldJournal 2012: 350826, 2012.

9. Nguyen BT, Park M, Pyun JC, Yoo YS and Kang MJ: Efficient PKC inhibitor screening achieved using a quantitative CE-LIF assay. Electrophoresis 37: 3146-3153, 2016.

10. Wang X, Tan C, Wang G, Cai JJ, Wang LP, Imperato-McGinley J and Zhu YS: Dual action of NSC606985 on cell growth and apoptosis mediated through PKC $\delta$ in prostatic cancer cells. Int J Oncol 51: 1601-1610, 2017.

11. Yin X, Zhang Y, Su J, Hou Y, Wang L, Ye X, Zhao Z, Zhou X, Li Y and Wang Z: Rottlerin exerts its anti-tumor activity through inhibition of Skp2 in breast cancer cells. Oncotarget 7: 66512-66524, 2016.
12. Lin CJ, Lin CY, Chen Y, Huang SH and Wang SM: Rottlerin inhibits migration of follicular thyroid carcinoma cells by PKCdelta-independent destabilization of the focal adhesion complex. J Cell Biochem 110: 428-437, 2010.

13. Su J, Wang L, Yin X, Zhao Z, Hou Y, Ye X, Zhou X and Wang Z: Rottlerin exhibits anti-cancer effect through inactivation of $\mathrm{S}$ phase kinase-associated protein 2 in pancreatic cancer cells. Am J Cancer Res 6: 2178-2191, 2016.

14. Mizushima N and Klionsky DJ: Protein turnover via autophagy: Implications for metabolism. Annu Rev Nutr 27: 19-40, 2007.

15. Choi KS: Autophagy and cancer. Exp Mol Med 44: 109-120, 2012.

16. Choi AM, Ryter SW and Levine B: Autophagy in human health and disease. N Engl J Med 368: 651-662, 2013.

17. Morselli E, Galluzzi L, Kepp O, Vicencio JM, Criollo A, Maiuri MC and Kroemer G: Anti- and pro-tumor functions of autophagy. Biochim Biophys Acta 1793: 1524-1532, 2009.

18. Brech A, Ahlquist T, Lothe RA and Stenmark H: Autophagy in tumour suppression and promotion. Mol Oncol 3: 366-375, 2009.

19. Moretti L, Yang ES, Kim KW and Lu B: Autophagy signaling in cancer and its potential as novel target to improve anticancer therapy. Drug Resist Updat 10: 135-143, 2007.

20. Kumar D, Shankar S and Srivastava RK: Rottlerin induces autophagy and apoptosis in prostate cancer stem cells via PI3K/Akt/mTOR signaling pathway. Cancer Lett 343: 179-189, 2014.

21. Song KS, Kim JS, Yun EJ, Kim YR, Seo KS, Park JH, Jung YJ, Park JI, Kweon GR, Yoon WH, et al: Rottlerin induces autophagy and apoptotic cell death through a PKC-delta-independent pathway in HT1080 human fibrosarcoma cells: The protective role of autophagy in apoptosis. Autophagy 4: 650-658, 2008.

22. Torricelli C, Daveri E, Salvadori S, Valacchi G, Ietta F, Muscettola M, Carlucci F and Maioli E: Phosphorylation-independent mTORC1 inhibition by the autophagy inducer Rottlerin. Cancer Lett 360: 17-27, 2015.

23. Livak KJ and Schmittgen TD: Analysis of relative gene expression data using real-time quantitative PCR and the 2(-Delta Delta C(T)) method. Methods 25: 402-408, 2001.

24. Parmer TG, Ward MD and Hait WN: Effects of rottlerin, an inhibitor of calmodulin-dependent protein kinase III, on cellular proliferation, viability, and cell cycle distribution in malignant glioma cells. Cell Growth Differ 8: 327-334, 1997.

25. Deretic V, Delgado M, Vergne I, Master S, De Haro S, Ponpuak M and Singh S: Autophagy in immunity against mycobacterium tuberculosis: A model system to dissect immunological roles of autophagy. Curr Top Microbiol Immunol 335: 169-188, 2009.

26. Ohno I, Eibl G, Odinokova I, Edderkaoui M, Damoiseaux RD, Yazbec M, Abrol R, Goddard WA III, Yokosuka O, Pandol SJ and Gukovskaya AS: Rottlerin stimulates apoptosis in pancreatic cancer cells through interactions with proteins of the Bcl-2 family. Am J Physiol Gastrointest Liver Physiol 298: G63-G73, 2010.

27. Matsui N, Yoshioka R, Nozawa A, Kobayashi N, Shichijo Y, Yoshikawa T and Akagi M: Caspase-independent apoptosis induced by reperfusion following ischemia without bile duct occlusion in rat liver. Biol Pharm Bull 40: 104-107, 2017.

28. Zhang M, Harashima N, Moritani T, Huang W and Harada M: The roles of ROS and caspases in TRAIL-induced apoptosis and necroptosis in human pancreatic cancer cells. PLoS One 10: e0127386, 2015.

29. Torricelli C, Salvadori S, Valacchi G, Souček K, Slabáková E, Muscettola M, Volpi N and Maioli E: Alternative pathways of cancer cell death by rottlerin: Apoptosis versus autophagy. Evid Based Complement Alternat Med 2012: 980658, 2012.

30. Wu H, Wang Y, Wang X, Li R and Yin D: MicroRNA-365 accelerates cardiac hypertrophy by inhibiting autophagy via the modulation of Skp2 expression. Biochem Biophys Res Commun 484: 304-310, 2017.

31. Chang HM, Okwuosa TM, Scarabelli T, Moudgil R and Yeh ETH: Cardiovascular complications of cancer therapy: Best practices in diagnosis, prevention, and management: Part 2. J Am Coll Cardiol 70: 2552-2565, 2017.

32. Kidane B, Sulman J, Xu W, Kong QQ, Wong R, Knox JJ and Darling GE: Baseline measure of health-related quality of life (Functional Assessment of Cancer Therapy-Esophagus) is associated with overall survival in patients with esophageal cancer. J Thorac Cardiovasc Surg 151: 1571-1580, 2016.

33. Ngo D, Jia JB, Green CS, Gulati AT and Lall C: Cancer therapy related complications in the liver, pancreas, and biliary system: An imaging perspective. Insights Imaging 6: 665-677, 2015. 
34. Tuorkey MJ: Cancer therapy with phytochemicals: Present and future perspectives. Biomed Environ Sci 28: 808-819, 2015.

35. Rao CV, Wang CX, Simi B, Lubet R, Kelloff G, Steele V and Reddy BS: Enhancement of experimental colon cancer by genistein. Cancer Res 57: 3717-3722, 1997.

36. Siddique YH, Ara G, Beg T, Gupta J and Afzal M: Assessment of cell viability, lipid peroxidation and quantification of DNA fragmentation after the treatment of anticancerous drug mitomycin $\mathrm{C}$ and curcumin in cultured human blood lymphocytes. Exp Toxicol Pathol 62: 503-508, 2010.

37. Basu A, Adkins B and Basu C: Down-regulation of caspase-2 by rottlerin via protein kinase $\mathrm{C}$-delta-independent pathway. Cancer Res 68: 2795-2802, 2008.

38. Zhao Z, Zheng N, Wang L, Hou Y, Zhou X and Wang Z: Rottlerin exhibits antitumor activity via down-regulation of TAZ in non-small cell lung cancer. Oncotarget 8: 7827-7838, 2017.

39. Ashkenazi A and Dixit VM: Death receptors: Signaling and modulation. Science 281: 1305-1308, 1998

40. Parrish AB, Freel CD and Kornbluth S: Cellular mechanisms controlling caspase activation and function. Cold Spring Harb Perspect Biol 5: a008672, 2013.

41. Shukla S, Fu P and Gupta S: Apigenin induces apoptosis by targeting inhibitor of apoptosis proteins and $\mathrm{Ku} 70$-Bax interaction in prostate cancer. Apoptosis 19: 883-894, 2014

42. Podmirseg SR, Jakel H, Ranches GD, Kullmann MK, Sohm B, Villunger A, Lindner $\mathrm{H}$ and Hengst L: Caspases uncouple p27(Kip1) from cell cycle regulated degradation and abolish its ability to stimulate cell migration and invasion. Oncogene 35 : 4580-4590, 2016.

43. Yoneyama M, Shiba T, Yamaguchi T and Ogita K: Possible involvement of caspases in proliferation of neocortical neural stem/progenitor cells in the developing mouse brain. Biol Pharm Bull 37: 1699-1703, 2014.

44. Frejlich E, Rudno-Rudzińska J, Janiszewski K, Salomon L, Kotulski K, Pelzer O, Grzebieniak Z, Tarnawa R and Kielan W: Caspases and their role in gastric cancer. Adv Clin Exp Med 22: 593-602, 2013

45. Singh BN, Kumar D, Shankar S and Srivastava RK: Rottlerin induces autophagy which leads to apoptotic cell death through inhibition of PI3K/Akt/mTOR pathway in human pancreatic cancer stem cells. Biochem Pharmacol 84: 1154-1163, 2012.
46. Ouyang L, Zhang L, Fu L and Liu B: A small-molecule activator induces ULK1-modulating autophagy-associated cell death in triple negative breast cancer. Autophagy 13: 777-778, 2017.

47. Sun L, Hu L, Cogdell D, Lu L, Gao C, Tian W, Zhang Z, Kang Y, Fleming JB and Zhang W: MIR506 induces autophagy-related cell death in pancreatic cancer cells by targeting the STAT3 pathway. Autophagy 13: 703-714, 2017.

48. Parzych KR and Klionsky DJ: An overview of autophagy: Morphology, mechanism, and regulation. Antioxid Redox Signal 20: 460-473, 2014.

49. Yu T, Guo F, Yu Y, Sun T, Ma D, Han J, Qian Y, Kryczek I, Sun D, Nagarsheth $\mathrm{N}$, et al: Fusobacterium nucleatum promotes chemoresistance to colorectal cancer by modulating autophagy. Cell 170: 548-563.e516, 2017.

50. Panneerdoss S, Viswanadhapalli $S$ and Abdelfattah $\mathrm{N}$, Onyeagucha BC, Timilsina S, Mohammad TA, Chen Y, Drake M, Vuori K, Kumar TR and Rao MK: Cross-talk between miR-471-5p and autophagy component proteins regulates LC3-associated phagocytosis (LAP) of apoptotic germ cells. Nat Commun 8: 598, 2017.

51. Rivera Vargas T, Cai Z, Shen Y, Dosset M, Benoit-Lizon I, Martin T, Roussey A, Flavell RA, Ghiringhelli F and Apetoh L: Selective degradation of PU.1 during autophagy represses the differentiation and antitumour activity of $\mathrm{T}_{\mathrm{H}} 9$ cells. Nat Commun 8: 559, 2017.

52. Levy JMM, Towers CG and Thorburn A: Targeting autophagy in cancer. Nat Rev Cancer 17: 528-542, 2017.

53. Goldsmith J, Levine B and Debnath J: Autophagy and cancer metabolism. Methods Enzymol 542: 25-57, 2014.

54. Edinger AL and Thompson CB: Death by design: Apoptosis, necrosis and autophagy. Curr Opin Cell Biol 16: 663-669, 2004.

55. Mills KR, Reginato M, Debnath J, Queenan B and Brugge JS: Tumor necrosis factor-related apoptosis-inducing ligand (TRAIL) is required for induction of autophagy during lumen formation in vitro. Proc Natl Acad Sci USA 101: 3438-3443, 2004

This work is licensed under a Creative Commons Attribution-NonCommercial-NoDerivatives 4.0 International (CC BY-NC-ND 4.0) License. 